\title{
O FACEBOOK COMO CONFESSIONÁRIO: DISCURSOS SOBRE SI E O INVESTIMENTO DOS PODERES
}

\author{
FACEBOOK AS CONFESSIONARY: DISCOURSES ON ITSELF AND THE \\ POWER INVESTMENTS
}

\section{Renato Levin Borges}

Mestrando no Programa de PósGraduação em Educação no Grupo Temático Educação em Saúde da Universidade Federal do Rio Grande do Sul, Bacharel e Licenciado em Filosofia pela Pontifícia Universidade do Rio Grande do Sul. Email: renato_levinborges@yahoo. com.br

\section{Ricardo Burg Ceccim}

Pós-doutor em antropologia médica, Programa de PósGraduação em Educação e Programa de Pós-Graduação em Saúde Coletiva, Professor Titular na área de Saúde Coletiva na Universidade Federal do Rio Grande do Sul.

Email: ricardo@ceccim.com.br

\section{Resumo}

Analisa-se o Facebook como modulação do dispositivo confessional cristão, em que um sujeito é instado, incessantemente, a produzir discursos sobre si, produzindo e sendo produzido por tramas de poder em um jogo de autorregulação. Para tal objetivo vale-se da análise de discurso foucaultiana, literatura sobre o manejo das informações por empresas e governos, assim como a legislação estado-unidense sobre usos de informações na internet e o caso wikileaks com as denúncias do exfuncionário da Agência de Inteligência Americana Edward Snowden. Discute-se os processos colocados em circulação para a produção de discursos sobre si tanto no confessionário quanto no site de relacionamentos, e como isso pode se relacionar com um trabalho da subjetividade sobre si mesma, produtora de saberes geradores de novos mecanismos de investimentos. Toma-se por conclusão a hipótese que o dispositivo de produção de discursos seja da ordem do funcionamento dos poderes e seus subsequentes investimentos, tanto na ordem governamental, quanto de ordem capitalística.

Palavras - chaves: Subjetividade; Confessionário; Investimento dos Poderes; Facebook; Foucault. 


\section{Abstract}

The article analyzes the Facebook as a modulation of the Christian confessional device, in which a subject is asked incessantly to produce discourses on itself, producing and being produced by power webs in a self-regulation game. In order to achieve this goal avails itself of Foucault's discourse analysis, literature on the management of information by companies and governments, as well the US legislation on information uses on the Internet and the wikileaks case with the accusations of the former employee of the American Intelligence Agency Edward Snowden. It discusses the processes put into circulation for the production of discourses on itself both in the confessional and in the social networking site, and how it can relate to a job of subjectivity on itself, producer of knowledges generators of new investment mechanisms. It is taken as conclusion the hypothesis that the discourse producing device is needed from the operation of powers policy and its subsequent investments in both the governmental order, as the capitalistic order.

Keywords: Subjectivity; Confessionary; Powers Investments; Facebook; Foucault.

\section{Introdução}

Em A Ordem do Discurso, aula inaugural no Collège de France proferida em 2 de dezembro de 1970, quando de sua nomeação para assumir o posto que fora de seu antigo professor Jean Hyppolite, Michel Foucault logo coloca a seguinte questão: "Mas, o que há, enfim, de tão perigoso no fato de as pessoas falarem e de seus discursos proliferarem indefinidamente? Onde, afinal, está o perigo?."1:8 Buscando compreender qual o papel dos discursos em sua dupla inscrição - de ponto de ação de poderes e de constituição de subjetividades - traçaremos breve esboço dessas inscrições na rede social mais utilizada atualmente, o Facebook. Buscamos, com esse "ensaio/ experimento" apreender processos que estão em jogo nesse plano virtual-real de produção "voluntária" de discursos, em especial, discursos sobre si, e traçar relação com o Facebook como dispositivo que insta a falar tal qual o confessionário cristão conceito que nos servirá de suporte para pensarmos esse novo plano de inscrição de discursos. Quais técnicas de poder instam a falar ininterruptamente e quais são seus interesses e investimentos de poder ordens do capital, técnicas de subjetivação e biopoder - incidentes exatamente sobre uma profusão de discursos.

É necessário esclarecer o que Foucault propõe como poder, discurso e dispositivo cristão do confessionário, atrelamento saber-poder que cria o plano de inscrição onde as técnicas de poder - assim como as técnicas de si e sobre si - possibilitam processos de subjetivação. Não é interesse estabelecer juízos de valor sobre as práticas de uso e os discursos no Facebook, mas pensar as engrenagens colocadas em processo nesse ambiente e como seu produto, os discursos, estabelecem áreas de contato e planos de investimento das técnicas de poder. Para começarmos a nos desvencilhar dos possíveis mal-entendidos sobre o poder, passemos à proposição positiva de poder em Foucault.

\section{poder como máquina produtiva}

Parece que toda vez que se fala em poder tem-se em mente alguma entidade substancial que concentra e emana poderes. 
Esse poder invariavelmente encontra-se em outro lugar e se dá a conhecer por seu caráter negativo: seja por meio de repressão, submissão, proibições de toda ordem, interdição de agires ou determinação dos modos de existir. Em suma, esse modo de representar o poder em sua condição paradoxal de aparecer no negativo, que só é presente em sua ausência, poderíamos chamar de tese repressiva ou negativa do poder. O poder - os poderes - para Foucault são da ordem das forças, e essas produtivas. Não se trata de uma posse, seja de um determinado grupo humano, seja do Estado. Foucault demonstra que "não é assim, nem disso, que procede o poder."2:35 O poder seria "menos uma propriedade que uma estratégia", e seus efeitos não seriam "atribuídos a uma apropriação, mas a disposições, a manobras, táticas, técnicas, funcionamentos." ${ }^{2: 35} \mathrm{O}$ poder "se exerce mais do que se possui, não é privilégio adquirido ou conservado da classe dominante, mas o efeito de conjunto de suas posições estratégicas." ${ }^{2: 35}$

Quando representamos uma classe social como detentora do poder, ou mesmo o Estado, tomamos o poder como substância, como algo que se pode possuir. O próprio Estado é efeito de engrenagens de poder: o poder é, portanto, difuso, por isso, não é localizável e impõe a necessidade de pensarmos suas relações e processos mais do que sua artificial centralidade em uma máquina estatal. Evocamos aqui a influência nietzschiana como um eco afirmando que onde há relações entre seres vivos, há relações de poder. $\mathrm{O}$ que se quer afirmar é que o poder é operatório e não é substância, portanto, não possui essência. "O poder produz realidade, antes de reprimir. E também produz verdade, antes de ideologizar, antes de abstrair ou mascarar." $2: 38$

Nesse sentido, é possível falar em tese positiva do poder: positiva porque produz e faz produzir. Como então o discurso passa a ter relevância aos poderes? Primeiro porque há um atrelamento entre saber e poder. Saber e poder implicam-se mutuamente, embora a prática de poder seja irredutível ao saber. Sobre essa mútua implicação saber-poder, em uma breve passagem do primeiro volume de História da Sexualidade I: a vontade de saber, Foucault diz: "Entre técnicas de saber e estratégias de poder, nenhuma exterioridade, ainda que cada uma tenha seu papel específico e que se articulem entre si, a partir de suas diferenças." ${ }^{\prime: 92-93}$ Embora o poder não seja redutível ao saber, é necessário que compreendamos que o poder engendra saberes. Assim seguimos na direção dos discursos. Essa implicação mútua "saberpoder", ocorre do seguinte modo: "temos que admitir que o poder produz saber" ${ }^{\prime \prime 30}$, não simplesmente favorecendo-o porque o serve ou aplicando-o porque útil; temos que admitir "que poder e saber estão diretamente implicados; que não há relação de poder sem a constituição correlata de um campo de saber, nem saber que não suponha e não constitua ao mesmo tempo relações de poder." ${ }^{\text {: } 30}$

Essas relações de "poder-saber" não devem ser analisadas a partir de um sujeito de conhecimento que seria ou não livre em relação ao sistema de poder; (...) é preciso considerar ao contrário que o sujeito que conhece, os objetos a conhecer e as modalidades de conhecimento são outros tantos efeitos dessas implicações fundamentais do poder-saber e de suas transformações históricas. Resumindo, não é a atividade do conhecimento que produziria um saber, útil ou arredio ao poder, mas o poder-saber, os processos e as lutas que o atravessam e o constituem, que determinam as formas e os campos possíveis do conhecimento. ${ }^{4: 30}$ 


\section{Por que o discurso importa?}

O que são os discursos é o que precisamos responder - mesmo que rapidamente - para buscarmos pensar os processos que continuamente os produzem e os investem. Em A Vontade de Saber, Foucault define que:

[...] os discursos são elementos ou blocos táticos no campo das correlações de força; podem existir discursos diferentes e mesmo contraditórios dentro de uma mesma estratégia; podem, ao contrário, circular sem mudar de forma entre estratégias opostas. ${ }^{3: 96}$

Se os poderes tecem saberes, é no discurso que os poderes veiculam o que produzem e instam a produzir, operando nos dois sentidos, isto é, na produção e captura dos discursos. Que haja engrenagens como o Estado e o mercado e que essas se saturem com a produção de modulações de estratégias de poder e captura de saberes isso não indica que, para Foucault, haja alguma ontologia dos centros de poder, onde Estado e capital desfrutariam de posição privilegiada ou posição primeira na ordem dos saberes-poderes.

Quando falamos das capturas é necessário entender que o próprio discurso não é uma espécie de significante puro e simples que traduziria relações e acontecimentos, ele próprio é campo de embate de forças, ou seja, dentre os inúmeros jogos de poder que é possível jogar, a ordem do discurso é talvez o plano de inscrição dos poderes mais importante: tanto para cooptar como para fazer rachar. Espaço de rachadura das técnicas e estratégias do poder no discurso porque esse não existe sem possibilitar resistência.

Há uma crítica que se dirige à relevância da ordem do discurso no pensamento foucaultiano que postula que há sobrevalorização do discurso nas relações de poder.

Por mais que o discurso seja aparentemente bem pouca coisa, as interdições que 0 atingem revelam logo, rapidamente, sua ligação com o desejo e com o poder. [...] o discurso não é simplesmente aquilo que traduz as lutas ou os sistemas de dominação, mas aquilo por que, pelo que se luta, o poder do qual nos queremos apoderar. ${ }^{1: 10}$

Entretanto, mesmo que Foucault reconheça que o discurso não é simples tradutor, compreende por outro lado que a própria profusão e determinadas maneiras de sobrevalorizar o discurso podem ser usadas como estratégia dos poderes para diminuir as tensões e afastar os acontecimentos que engendram e são engendrados nos discursos, delimitandoos e os confinando ao campo da linguagem - ou como Deleuze diria, ao plano da pura tagarelice:

Ora, parece-me que sob esta aparente veneração do discurso, sob essa aparente logofilia, esconde-se uma espécie de temor. Tudo se passa como se interdições, supressões, fronteiras e limites tivessem sido dispostos de modo a dominar, ao menos em parte, a grande proliferação do discurso. De modo a que sua riqueza fosse aliviada de sua parte mais perigosa e que sua desordem fosse organizada segundo figuras que esquivassem o mais incontrolável: tudo se passa como se tivessem querido apagar até as marcas de sua irrupção nos jogos do pensamento e da língua. Há, sem dúvida, em nossa sociedade e, imagino, em todas as outras, mas segundo um perfil e facetas diferentes, uma profunda logofobia, uma espécie de temor surdo desses acontecimentos, dessa massa de coisas ditas, do surgir de todos 
esses enunciados, de tudo o que possa haver aí de violento, de descontínuo, de combativo, de desordem, também, e de perigoso, desse grande zumbido incessante e desordenado do discurso. ${ }^{1: 50}$

Será no século XVII que será posta a necessidade de produção de discursos sobre si, para de um lado dizer incessantemente verdades sobre si - eu devo confessar! Eu devo dizer a verdade! Por outro lado, constituir processos de subjetivação que durante e no processo de produzir verdade sobre si - se constituirão, se centrarão e se reorganizarão em um enfoque que culminará em um eu subjetivo que traça as (e se atrela às) representações de si, que agencia um plano de inscrição aos poderes.

Constituindo e investindo esse plano de inscrição encontraremos, no cristianismo, o dispositivo do confessionário.

\section{O confessionário e o Facebook}

No curso Os Anormais, anos de 1974 e 1975, Foucault identifica nos séculos IX, X e XI o germe da prática da confissão entre os leigos. $O$ objetivo dessa prática era envergonhar-se diante dos pecados cometidos, mas ainda não se tratava do dispositivo do confessionário. Os objetivos que levarão à criação do confessionário serão em grande parte diversos, contudo, cumpre notar que nesse período o princípio da revelação do pecado é colocado em funcionamento, isto é, as engrenagens da produção de verdades sobre si - dirigidas nesses séculos às autoridades religiosas, a qual exercerá, por seu turno, o poder de aplicar penitências para a expiação dos pecados - investindo sujeitos (o assujeitamento).

Será somente no século XIII que serão instados os infiéis a se confessarem regularmente, sendo que essa confissão terá que ocorrer novamente direcionada aos clérigos com a frequência de pelo menos uma vez por mês, ou até mesmo uma vez por semana, mesmo que não haja mais pecados a confessar como anteriormente se requeria: confessar quando pecasse e poder confessar para leigos já que o objetivo era envergonhar-se.

Dirá Foucault que a Igreja retomará para si a função de receptor e condutor das confissões, instando que o indivíduo produza verdade sobre si incessantemente: "enfim, e sobretudo, obrigação de exaustividade. Não bastará dizer o pecado no momento em que foi cometido, e por achá-lo particularmente grave. [Será] preciso enunciar todos os pecados, não apenas os graves, [...] também os que são menos graves." ${ }^{\text {5:220-221 }}$ A partir dessa produção continua e infindável se constituirá o plano de inscrição da autoridade eclesiástica:

[...] cabe ao padre manipular essa sutilíssima distinção que os teólogos fazem entre pecado venial e pecado mortal, que, como vocês sabem, podem se transformar um no outro, conforme as circunstâncias, conforme o tempo de ação, conforme as pessoas etc. Portanto, existe a obrigação de regularidade, de continuidade, de exaustividade..$^{5: 221}$

As três características do dispositivo confessionário estão postas: regularidade na produção de verdade sobre si e continuidade, isto é, certa regularidade no falar sobre si e de si, e exaustividade dos discursos, falar ininterruptamente, infinitamente. Temos nesses três elementos as engrenagens que colocam em funcionamento tanto o confessionário quanto o dispositivo moderno do Facebook.

O que no século XIII garante esses três elementos são a regularidade requerida pelo padre para que o fiel se confesse (e 
o fiel via de regra se confessará graças a autoridade que o padre exerce sobre ele); a necessidade de continuidade, o que significa que a partir de então não será mais episódica a necessidade de se confessar, mas constituir-se-á um ciclo temporal para tal (o elemento fundante será a confissão geral e anual); e por fim, o que garantirá a exaustividade será uma torção da condição do padre de receptáculo passivo - fala o fiel quando quer e do modo que quer para a condição ativa de extrator: o fiel será perguntado, pressionado, terá suas palavras direcionadas, controladas, e será, sobretudo, instado a responder o que o padre quer saber.

É necessário compreender que esse mecanismo da produção de discursos sobre si do confessionário é colocado em movimento em torno da noção de revelação e é exatamente porque só poderá haver absolvição por meio da revelação que a confissão se constitui um elemento essencial para os poderes, passando a se atribuir o direito de exame. É no direito do exame que o poder da pastoral cristã e posteriormente dos Estados modernos - formará o "poder empírico do olho, do olhar, do ouvido, da audição do padre." 5:224 Isso significa que para melhor governar as almas, toda uma série de mecanismos será colocada em funcionamento e essa se rearticulará infinitamente para que haja olhos e seus ouvidos em todas as partes.
Figura 1 - Facebook como confessionário, por Paweł Kuczyński

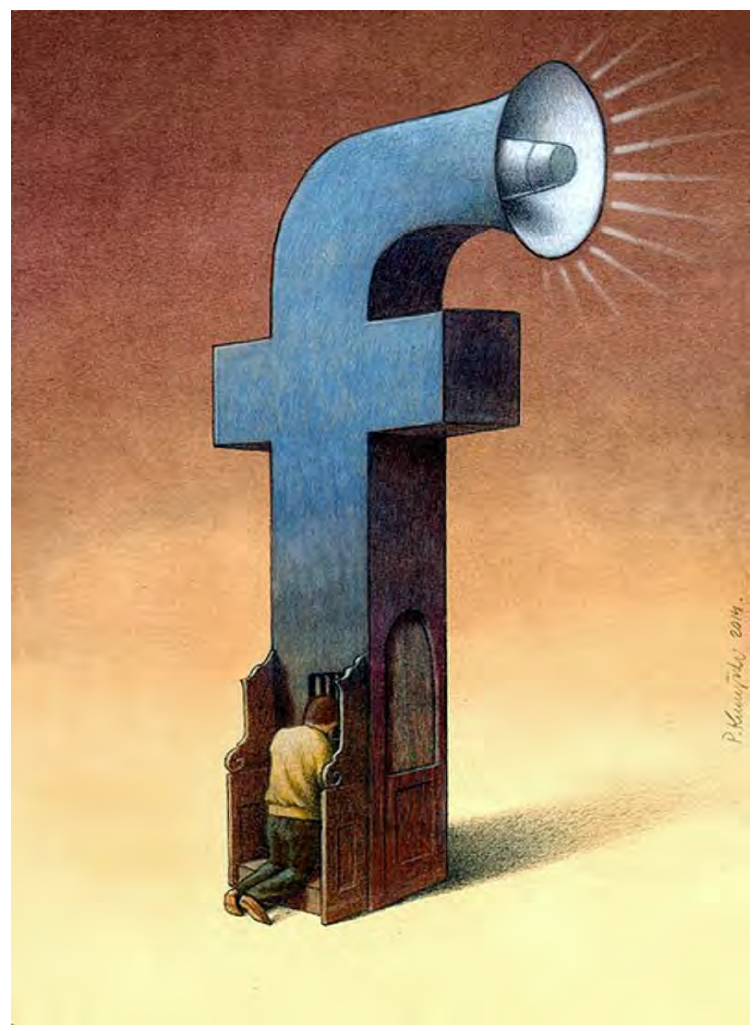

Fonte: Kuczyński. ${ }^{5}$

Consideremos o Facebook como modulação do confessionário. As três regras que colocam em funcionamento o confessionário estão também presentes no site: regularidade de produção discursiva, periodicidade - mesmo que não fixa, se é sempre instado a criar discursos - e a exaustividade, isso é, falar o tempo todo, sobre tudo e especialmente sobre si. Entretanto, a operação aqui é mais sutil. Os discursos sobre si do Facebook operam um jogo duplo onde o sujeito fornece substrato às técnicas de poder ao mesmo tempo em que - de modo retificado - reinveste em um núcleo subjetivo: constitui para si um eu que se inscreve em determinado espectro de identidade. Parece-nos que esse centramento artificial operado pelo próprio sujeito ao produzir verdades sobre si é a superfície de contato (ponto de inflexão) 
dos investimentos dos poderes: esses miram a subjetividade entendida como representação de si e centramento operado pelo sujeito na emissão de discursos que, de algum modo, Ihe possibilitaria atos de liberação ou de liberdade.

A pergunta "o que você está pensando?", insertada no espaço para postagem no Facebook se afigura emblemática por sua solicitação continua para que se produza discursos a partir de si e sobre si. Aproximemos mais o dispositivo do confessionário ao Facebook: os processos colocados em prática pela igreja com o confessionário são análogos à torrente infindável de produção no site de relacionamentos:

Na verdade, tudo isso se cristalizou no interior de uma instituição, ou antes, de um pequeno objeto, de um pequeno móvel, que vocês conhecem bem e que é o confessionário: o confessionário como lugar aberto, anônimo, público, presente dentro da igreja, onde um fiel pode vir se apresentar e onde encontrará sempre à sua disposição um padre que o ouvirá, ao lado do qual ele se vê imediatamente situado, mas do qual, apesar disso, é separado por uma cortininha ou pequena grade. ${ }^{5: 229}$

Ao contrário da posição que ocupava o padre na confissão, no Facebook não há medição para penitência, há coleta de sinais, dados, informações, desejos e tudo isso servindo aos mais variados usos, como se não mais se introduzisse a vida do indivíduo ao exame do padre, mas sim ao exame geral. Importante é que haja um dispositivo em processo contínuo de incitação de produção das mais diversas ordens de discurso; importa que ele, o dispositivo, sempre acolhe a produção para os mais variados usos.

Nesse breve ensaio sobre as relações discursivas e os poderes buscamos pensar os investimentos dos poderes nos discursos (assim como nos silêncios que instauram) produzidos pelo sujeito (como em Foucault), quase como método: "buscar as instâncias de produção discursiva (que, evidentemente, também organizam silêncios), de produção de poder (que, algumas vezes têm a função de interditar), das produções de saber (as quais, frequentemente, fazem circular erros ou desconhecimentos sistemáticos)"3:17, como explica Foucault. Passemos rapidamente a alguns poderes dessa discursividade incessante produzida no Facebook.

\section{Investimento do capital}

Qualquer pessoa que já tenha procurado por alguma coisa em sites de busca e logo após tenha entrado no Facebook já reparou que no corpo do site há uma série de sugestões de produtos relacionadas à pesquisa feita anteriormente. Por exemplo: se uma pessoa pesquisa sobre cafeteiras, uma série de ofertas aparecerá em sua página no Facebook. Mesmo quando a pesquisa não é sobre um produto, como por exemplo, pesquisar sobre Nietzsche, invariavelmente o Facebook sugerirá desde livros de Nietzsche até canecas com seu rosto, passando por camisetas com frases de impacto do filósofo, dentre outros produtos inimagináveis ligando a imagem do pensador a uma gama infindável de artigos de consumo. A ferramenta de localização, também, funcionará como sugestão de lugares a visitar, amigos a encontrar etc. A mesma ferramenta assinalará para todos aonde você está e, a você, quem de sua rede de amigos está por perto. As dicas passarão a incluir a língua do país onde esteja e as inserções comerciais passarão a ser do país em que esteja. 
Segundo artigo da revista Time de fevereiro de 20147 ${ }^{7}$, há sete usos das informações dos usuários do Facebook investidas pelos fluxos do capital. $O$ primeiro uso diz respeito a uma espécie de repositório de informações que não podem nunca ser apagadas do servidor do site. Isto significa que mesmo que o usuário opte por deletar sua conta, seus dados nunca serão totalmente excluídos do servidor. Há então uma saturação e compilação de dados e essa técnica se liga às posteriores. O segundo uso diz respeito à utilização não consentida do usuário para fins propagandísticos do consumidor de produtos comprados pela Internet - e inclusive fora dela, segundo convênios do Facebook com companhias coletoras de dados como a Datalogix, Acxiom, Epsilon e BlueKai, essas possuindo contrato com lojas físicas que repassam os dados $^{8}-$, tornamo-nos garotos ou garotas propaganda sem sabermos. O terceiro modo está atrelado ao segundo, já que o Facebook coleta dados mesmo quando o computador encontra-se desconectado da Internet. O site coleta dados por até 90 dias valendo-se dos cookies, espécie de arquivos depositados no computador através da conexão com variados sites, esses coletam os dados do usuário para enviá-los ao site que armazena e direciona suas estratégias de investimento a partir desse importante processo de traçar perfis de consumo.

O quarto uso diz respeito à opção "curtir" também sendo usado com fins de propaganda (involuntária) pelas empresas no Facebook. O artigo da Time fala no quinto - e mais relevante para nossos propósitos - uso do site: em verdade, não se trata puramente de uso, mas da obrigação imposta de verdade. Ocorre que anteriormente era possível criar uma conta com nome falso, informações falsas sobre sua localização e até mesmo ocultar seu perfil da busca de outros usuários. Gradualmente o site passou a exigir nome e sobrenome verdadeiros e tornou impossível optar por não ser possível que outros usuários encontrem páginas pessoais de quaisquer outras pessoas que tenham cadastro no site.

O sétimo uso desses dados é o tráfego de informações entre Facebook e Estado, assunto que abordaremos a seguir. Muito embora não seja nosso propósito aprofundarmo-nos na discussão dos usos dos discursos pelos poderes, mas traçar um mapa, ou um breve sobrevoo por esse plano, cremos ser relevante sinalizar que essa problemática se inscreve na discussão mais ampla foucaultiana de biopoder enquanto se ocupa da sujeição dos corpos e controle das populações.

\section{Investimento do Estado}

Em 1974, nos Estados Unidos da América, o então presidente Richard Nixon renuncia por causa do escândalo gerado pela revelação de que havia sido criada uma rede de espionagem para ajudá-lo a se reeleger em 1972. Como resposta ao escândalo conhecido como Watergateii, é criada e aprovada pelo Senado estado-unidense a emenda conhecida pela sigla FISA (Foreign Intelligence Surveillance Act ou Lei de Vigilância de Inteligência Estrangeira) que determina os procedimentos para a vigilância física e eletrônica e coleta de informação de inteligência estrangeira, mantendo a necessidade de mandatos judiciais para investigar cidadãos estadounidenses e tomando como único critério

i O termo biopoder, que já fora utilizado nos cursos no Collège de France a partir do seminário de 19751976, aparece como conceito no primeiro volume de História da sexualidade como: “[...] explosão, portanto, de técnicas diversas e numerosas para obterem a sujeição dos corpos e o controle das populações." 3:131

ii De acordo com o portal Watergate ${ }^{10}$, o escândalo de Watergate recebe o nome do hotel homônimo que costumava ser o ponto de encontro do Partido Democrata na capital Washington. 
para a obtenção de dados e vigilância de estrangeiros que seja demonstrado que o indivíduo investigado provavelmente faça parte de poder estrangeiro ou esteja a serviço de poderes estrangeiros.iii

A vigilância e a atenção aos discursos em meios virtuais receberam grande impulso a partir da emenda Patriota aprovada por George W. Bush após o ataque terrorista de 11 de setembro de 2001, adicionando à emenda de 1978 a possibilidade de "autorizar longos períodos de vigilância." ${ }^{9} \mathrm{O}$ texto da emenda não é preciso sobre quais tipos de procedimentos devem ser utilizados na vigilância e obtenção de informações, valendo-se (ao que os fatos posteriores parecem indicar) da própria imprecisão da lei, já que as denúncias contra o governo Bush de obtenção por meios ilegais virá à tona com o vazamento dos documentos por Edward Snowden em junho de 2013. Funcionário, à época, da Agência Nacional de Segurança dos Estados Unidos, Snowden tornou pública a existência do PRISM, nomecódigo do programa governamental para a obtenção de dados conhecida como SIGAD US-984XN ${ }^{12}$, criado sob o governo de George W. Bush e renovado quando estava prestes a expirar sua vigência pelo presidente Barack Obama em dezembro de $2012^{13}$ que foi primeiramente noticiado pelo The Guardian $^{13}$, na Inglaterra, e Washington Post $^{14}$, nos Estados Unidos.

O programa PRISM seria o modo com que efetivamente o governo estado-unidense obtinha massivamente dados por meios ilegais, "grampeando" diretamente os servidores-base dos sites com maior número de usuários, como o Facebook. Se, legalmente, o caminho para obtenção de dados pelo governo é por meio de mandatos judiciaisiv, o problema posto era

\footnotetext{
iii Todas informações aqui utilizadas sobre a emenda encontram-se disponíveis no site do Departamento de Justiça dos Estados Unidos da América. ${ }^{11}$

iv No ano de 2013, por exemplo, o governo dos Estados Unidos solicitou mais de $\mathbf{3 8 . 0 0 0}$ dados de usuários do Facebook, acatados em sua grande
}

a lentidão do procedimento legal e o interesse nas informações dos usuários ser imensamente superior aos casos onde eram cabíveis as quebras de sigilo de informação, além da proibição em demandar dados de cidadãos ou residentes em solo estado-unidense. Esses dados eram - e possivelmente ainda o são - buscados conforme o temor, interesse e possibilidade de investimento do Estado sobre os discursos, visto que o poder, embora nunca subjetivo, cria estratégias e técnicas visando determinados propósitos.

É relevante notar o grande investimento dos poderes do Estado sobre as mídias sociais, em especial por seu potencial de mobilização de outras tramas de poderes que potencialmente se opõem ou possibilitam outras relações além e aquém ao biopoder dos Estados modernos ocidentais.

\section{Considerações Finais}

O problema colocado foi como se dão e onde se dão os investimentos dos poderes, no caso do Facebook, que possui mais de um bilhão de usuários ${ }^{17}$, onde exaustivamente se produzem discursos sobre si e compreender o jogo de cooptação contínua a partir dos fluxos do capital, das técnicas dos poderes para sujeição e controle das populações, concedendo ao Facebook posição estratégica como dispositivo de produção de verdades sobre si e como centro de tensão e inflexão dos investimentos polimorfos dos poderes.

Nosso propósito foi relacionar maioria, conforme notícia do The Guardian. ${ }^{15}$ Também há notícias de requerimento de dados de outros governos, em especial no ano de 2013, por países árabes buscando informações e modos de controle e disciplinamento das revoltas iniciadas no Egito. Recep Tayyip Erdogan, primeiro ministro da Turquia, país que solicitou dados ao Google, Yahoo e Twitter, dentre outros, chegou a afirmar em artigo ${ }^{16}$ que as mídias sociais são "as maiores ameaças à sociedade". 


\section{Artigo Original}

as técnicas sobre a discursividade na mais famosa e popular rede social da atualidade, assinalando os traços constitutivos de seu funcionamento ao dispositivo do confessionário cristão. O Facebook desponta como um novo plano de inscrição de discursos, insta a falar, fazendo-nos "confessar" regularmente, do ciclo temporal do cada dia ao sinal sonoro contínuo de notificações; mobilizando-nos continuamente pelo comentar, compartilhar ou curtir; e incitando à exaustividade pela necessidade da resposta e da interação ou mesmo da notificação de atos, lugares de estar e estados de ânimo. Investimento de biopoderes, produção da verdade sobre si, voz a ser emanada e vozes que retornam a cada publicação. Não se trata de ajuizar valor à complexidade das tramas de poderes implicadas na produção de discursos sobre si no Facebook em relação aos investimentos dos poderes. Verificamos possível constituir o confessionário foucaultiano como plano imanente ao Facebook, onde poderes atuam e são produzidos, em um jogo de forças que tem nessa rede social espaço de embate e disputa.

\section{Referências}

1. Foucault M. A ordem do discurso. São Paulo: Loyola; 1996.

². Deleuze G. Foucault. São Paulo: Brasiliense; 2005.

${ }^{3}$. Foucault M. História da sexualidade I: a vontade de saber. Rio de Janeiro: Graal; 1977.

${ }^{4}$. Foucault M. Vigiar e punir. Petrópolis: Vozes; 1975.

5. Foucault M. Os anormais: curso no Collège de France (1974-1975). São Paulo: Martins Fontes; 2001.

6. Kuczyńskl P. Confessional. 2014. 1 ilustração.

7. Luckerson V. 7 controversial ways Facebook has used your data. Time [Internet]. 2014 Feb 4 [citado em 2015 Mar 25]. Disponível em: http://time.com/4695/7-controversial-waysFacebook-has-used-your-data/

${ }^{8}$. Klosowski T. How Facebook uses your data to target ads, even offline [Internet]. [S.I.]: Lifehacker; 2013 [citado em 2015 Mar 28]. Disponível em: http://lifehacker.com/5994380/ how-Facebook-uses-your-data-to-target-ads-even-offline.

9. AllGov. Foreign intelligence surveillance court [Internet]. [S.I.]: AllGov.com; c2015 [acesso citado em 2015 Mar 28]. Disponível em: http://www.allgov.com/departments/department-ofjustice/foreign-intelligence-surveillance-court?agencyid=7206_

10. Watergate. Watergate: the scandal that brought down Richard Nixon [Internet]. [S.I.]: Watergate, c1995-2015 [citado em 2015 Mar 28]. Disponível em: http://watergate.info/

11. U.S. Department of Justice. Office of Justice Programs. The Foreign Intelligence Surveillance Act of 1978 (FISA) [Internet]. Washington: OJP, 2013 [citado em 2015 Abr 3]. Disponível em: https://it.ojp.gov/default.aspx?area=privacy\&page $=1286$ 


\section{Artigo Original}

12. Chappell B. NSA reportedly mines servers of U.S. internet firms for data [Internet]. Washington: NPR, 2013 [citado em 2015 Mar 28]. Disponível em: http://www.npr.org/blogs/ thetwo-way/2013/06/06/189321612/nsa-reportedly-mines-servers-of-u-s-internet-firms-fordata

13. Greenwald G, Macaskill E. NSA Prism program taps in to user data of Apple, Google and others. The Guardian [Internet]. 2013 Jun 6 [citado em 2015 Mar 28]. Disponível em: http:// www.theguardian.com/world/2013/jun/06/us-tech-giants-nsa-data

${ }^{14}$. Washington Post. NSA slides explain the PRISM data-collection program [Internet]. $2013 \mathrm{Jul}$ 10 [citado em 2015 Mar 28]. Disponível em: http://www.washingtonpost.com/wp-srv/special/ politics/prism-collection-documents/

15. Rushe D. Facebook reveals governments asked for data on 38,000 users in 2013. The Guardian [Internet]. 2013 Aug 27 [citado em 2015 Mar 28]. Disponível em: http://www.theguardian. com/technology/2013/aug/27/Facebook-government-user-requests

${ }^{16}$. Letsch C. Social media and opposition to blame for protests, says Turkish PM. The Guardian [Internet]. 2013 Jun 2 [citado em 2015 Mar 28]. Disponível em: http://www.theguardian.com/ world/2013/jun/02/turkish-protesters-control-istanbul-square

17. Statistic Brain. Facebook statistics [Internet]. [S.I.]: Statistic Brain, 2015. Research date: 2015 January 27 [citado em 2015 Mar 28]. Disponível em: http://www.statisticbrain.com/ Facebook-statistics/ 